\title{
Commuting trade-offs and distance reduction in two-worker households
}

\author{
Julien Surprenant-Legault \\ Analyst \\ Agence métropolitaine de transport \\ Chargé d'études - Planification stratégique \\ Planification et innovations \\ Canada \\ Tel.: 514 287-2464, ext 4227 \\ Fax: 514 287-2460 \\ Email: jslegault@amt.qc.ca \\ Zachary Patterson \\ Assistant Professor \\ Department of Geography, Planning and Environment \\ Concordia University \\ Canada \\ Tel.: (514) 848-2424 ext. 3492 \\ Fax: (514) 848-2032 \\ E-mail: zachary.patterson(a,concordia.ca
}

\author{
Ahmed M. El-Geneidy \\ Associate Professor \\ School of Urban Planning \\ McGill University \\ Canada \\ Tel.: 514-398-8741 \\ Fax: 514-398-8376 \\ Email: ahmed.elgeneidy@mcgill.ca
}

For Citation please use: Surprenant-Legault, J., Patterson, Z., \& El-Geneidy, A. (2013). Commuting trade-offs and distance reduction in two-worker households. Transportation Research Part A: Policy and Practice, 51, 12-28.

Link to the version published in journal:

http://www.sciencedirect.com/science/article/pii/S0965856413000955 


\begin{abstract}
Two-worker households have received a great deal of attention in the academic literature pertaining to transportation and land use planning. Two-worker households are likely to play an increasingly important role in determining future transportation demand but their expected impact has been subject to debate. This research uses a novel approach to quantify the degree to which partner commute distance affects individual commute distance. It quantifies the degree to which partners adjust their behaviour to reduce total commute distance. It also provides empirical evidence that two-worker households do indeed adjust their residence workplace configuration to reduce commute distance. It does so through the use of an adaptation of common approaches to analyzing commute distance (modeling total as well as individual commute distances) with innovative variables inspired by the literature on household location and tenure. Findings from this study reconfirm the empirical research suggesting that members of two-worker households travel the same or less than one-worker households. They also confirm that partner commute distance has a positive impact on individual commute distance, suggesting partner commute distance is complementary. At the same time, it is shown that this does not imply that partner's do not trade-off commute distance, rather two-worker households apply strategies to decrease their total commuting distance. This research could help policy makers in better understanding the commuting patterns of two-worker households to help in adapting land use and transportation policies that can address the needs of this growing population group.
\end{abstract}

\title{
RESEARCH HIGHLIGHTS
}

- Two-worker households have received a great deal of attention in the academic literature pertaining to transportation and land use planning.

- This research uses a novel approach to quantify the degree to which partner commute distance affects individual commute distance.

- It quantifies the degree to which partners adjust their behaviour to reduce total commute distance.

- It provides empirical evidence that two-worker households do indeed adjust their residence workplace configuration to reduce commute distance. 


\section{INTRODUCTION}

Two-worker households have received a great deal of attention in the academic literature pertaining to transportation and land use planning. There are a few reasons for this. First, as Clark, Huang and Withers (2003) note, economic, social and demographic trends are expected to result in more two-worker households in the future. As a result, they are likely to play an increasingly important role in determining future transportation demand. Second, there has been a debate in the literature about the impact of two-worker households on transportation demand. At least since White (1988), there has been suspicion that two-worker households, finding it more difficult to optimize housing location with respect to job location, travel more than oneworker households. The implication of this is that more two-worker households will result in relatively more travel in the future. While it is intuitive that two-worker families ought to travel more than one-worker families, the empirical research that has emerged to approach this question has not been decisive, and it is not at all clear that two-worker families do travel more than oneworker families. Most empirical research has suggested that two-worker families commute about the same as (or even less) than one worker families. The excess-commuting literature has raised doubts about the usefulness of commute cost minimization in understanding residence household configurations and therefore commuting distance - doubts that are cast upon two-worker households as well.

The present paper examines these questions using regression models of commuting distance for households in Montreal that explicitly take into account partner commuting distance and home - work spatial configuration. The research allows us to reconcile previous findings. In particular, we find that: when controlling for socio-demographic variables, two-worker households commute less than one-worker households; while a partner's commute distance 
decreases commuting distance, this relationship is inelastic suggesting that trade-offs in commuting distance are indeed made in two-worker families; the angle between the work locations of two-worker households is an important indicator of total household commute distance; and that the positive coefficient of this variable also suggests that two-worker households adjust their household work configuration to reduce overall commuting distance. In other words, commuting distances in two-worker households are indeed complements to each other, but that does not mean that households do not trade-off commute distance, or adjust residence and work locations to reduce total commuting distance.

The paper continues with a literature review looking at previous research on two-worker households related to this research. After this, another section outlines the main questions to be asked in the paper and the methodological approach adopted to answer them. The case study region and the data used are then explained and this is followed by a description of the statistical models developed and their results. The paper is concluded with a discussion on what has been learned and some thoughts on pressing future directions for this research.

\section{LITERATURE REVIEW}

Two different streams of literature on two-worker households are relevant to this research. The first deals with commuting distance and times, and the second on geometric measures of household and job configuration.

\section{Commuting Distances and Times in Two-worker Households}

The first major stream of research on commuting distance of two-worker households has concentrated on the difference in commuting distances and times of men and women in twoworker households. The empirical evidence in this regard suggests that women travel shorter distances than men to go to work (Clark et al., 2003; Clark \& Wang, 2005; Gordon, Kumar, \& 
Richardson, 1989; Hanson \& Hanson, 1980; Johnston-Anumonwo, 1992; Madden, 1981; Marion \& Horner, 2007; Singell \& Lillydahl, 1986; Sultana, 2005, 2006; Van Ham \& Hooimeijer, 2009; M. J. White, 1977, 1986). One of the dominant explanations for this stylized fact is that women have more household responsibilities than men (Hanson \& Hanson, 1980; Johnston-Anumonwo, 1992; Madden, 1981; Turner \& Niemeier, 1997; M. J. White, 1977). Adding a local wrinkle to previous research, Shearmur (2006) observed for Montreal that men travel further to reach jobs located in one of five suburban employment nodes than they do to the central business district (CBD). Women, by contrast, travel farther to reach jobs in the CBD than they do to reach jobs in four of these suburban sub-centers. While not generally the focus of research, it is interesting to note that several researchers have participated in a debate around the effect of the presence of children on commuting time (Singell \& Lillydahl, 1986; M. J. White, 1986). Singell and Lillydahl (1986) observe a reduction in commuting times for both workers when children are present whereas White (1986) and Johnston- Anumonwo (1992), find the opposite. Others have also have looked at the question of children and their influence on family travel behavior (e.g. (Johansson, 2005; Zwerts, Allaert, Janssens, Wets, \& Witlox, 2010)).

Related to how far women commute relative to men in two-worker households is the question of whether two-worker households commute more than one-worker households. The increasing presence of two-worker households was already noticed in literature related to transportation and land use by the late 1970s. This led to theoretical models developed to explain household and work location (and thereby commute distance) of two-worker households (Curran, Carlson, \& Ford, 1982; Madden, 1980; M. J. White, 1977). These models, inspired by Alonso’s (1964) monocentric city model, resulted in household and location choices where commuting distances were traded-off against one another. It was not long after that researchers, 
particularly when examining issues of "excess commuting” (e.g. (M.J. White, 1988)) began to suspect two-worker households of commuting more than one-worker households. This made sense since two-worker households had more constraints when choosing household and employment location and as a result, it was reasoned, were less likely to find locations that would result in short commutes for both workers.

While intuitive, the empirical research that has considered travel commute distance of two- vs. one-worker households is by no means decisive. Kim (1995) examines the question of commute distance in the context of excess commuting by extending an approach inspired by Hamilton (1982) and later modified, by White (1988), Giuliano and Small (1993) and others. In these latter studies, excess commuting was defined as commuting over-and-above what would be required if the residential location of workers were matched with jobs so as to minimize commute distance. They are generally critical of models that allocate workers residences based on minimizing commuting costs. Kim (1995) extends this analysis to evaluate the excess commuting of two- vs. one-worker households. In doing so, he calculates average commute distance for one- and two-worker households. He makes a number of interesting findings. He finds first that average distance per worker for two-worker families is in fact lower than for oneworker families, even though this represents slightly more (41\% vs. $38 \%)$ excess commuting. These results vary quite a bit when other considerations such as type of work, housing tenure and race are taken into account. That said, he concludes that his results "support the belief that many economists have had that the basic urban model, in which work and residence location choice are based on the desire to minimize commuting distance, is not as weak a construct as recently perceived" making reference to earlier work on excess commuting. Research on excess commuting continues although not necessarily looking at the question of two-worker households 
(see e.g. (Boussauw, Neutens, \& Witlox, 2010; Boussauw, Van Acker, \& Witlox, 2012; Layman, 2010)).

Sultana (2005) examines the question by comparing commute times of one- and twoworker households directly. This research is done as a direct challenge to authors (e.g. (Giuliano $\&$ Small, 1993)) that had intimated that the use of jobs-housing balance as a policy goal would be mitigated by the increasing presence of two-worker households, since the ability of a twoworker household to choose residential locations close to both workplaces would be limited. Citing the fact that such a supposition had not been conclusively tested, she sought to compare commuting distance and time of two-worker households. Comparing average commute times between different family types as well as using regression analysis she concludes that her results challenge the assumption that average commute times of married couple dual-earner households are necessarily longer than single-earner households. In particular, she finds that in all cases "either there were no significant differences or the average commutes of single-earner households actually turned out to be longer" (p. 348).

A third author who explicitly considers two-worker commuting distance (and time) is Pnina Plaut (2006). Plaut endeavors, through the use of seemingly unrelated (SUR) regression techniques, to better understand the factors affecting travel time and distance of male and female spouses. Plaut does not explicitly examine differences between one- and two-worker households, but rather attempts to see whether there is a relationship between the commute times and distances of partners in the same household. It is for this reason that an SUR approach is used. The SUR approach makes it possible to capture correlation between two "seemingly unrelated" processes, in this case the travel times of male and female spouses. Plaut finds that there is a positive correlation between the first-stage residuals of travel distances and times of male and 
female spouses. She draws a number of important conclusions from this. First, she concludes that “commuting distances and times for spouses appear to be strongly complementary" (p. 569). Second, she concludes that "Spouses do not appear to be trading off one's commuting distance/time for the other's. Commute trips for both are adjusted together (both trips made longer or both shorter) as part of complex trade-offs..." (p. 569). It is important to recognize here that while Plaut is able to conclude there is a positive correlation between commute distances of partners in two-worker households, she is not able to measure this effect directly, i.e. if one partner's commute distance increases, by how much will the others? This is one question that research in this paper will broach.

A good part of the literature on two-worker households has looked specifically at the question of male vs. female commuting patterns in two-worker households. A second area of interest has considered two-worker households less with respect to gender dynamics and more about the commute distances as an outcome of household and work location outcomes for households.

Kim (1995) and Sultana (2005) find that average commutes are shorter in two- than in one-worker households. Kim's results rely on a trade-off (commute cost minimization) between commute distances of partners, and Sultana's results suggest such trade-offs to be the case. Plaut on the other hand concludes that such trade-offs are not made and that two-worker commute trips are complements of each other. As a result, there is an apparent confusion in the literature about whether or not partners in two-worker families actually do trade-off commute distances. With a new approach to this problem, we reconcile this confusion in the present paper. One of the innovative aspects of the approach adopted in this paper is to use geometric measures of 
household and employment configuration in our analyses - measures inspired by work in a different, but related literature on household location and tenure in two-worker households.

\section{Measures of Household and Employment Configuration}

In much of the literature on two-worker households, analysis has been based on straightforward measures of household-to-work travel time and distance in order to characterize the spatial configuration of households and their associated workplaces. That said, a complete literature review on the topic must also recognize the more creative measurements that have been used - particularly in the literature looking at household location and tenure.

For example, the distance between the two-worker household workplaces (see Error!

Reference source not found. (A)) has been used to explain job and residential search behaviour (Deding, Filges, \& van Ommeren, 2009; van Ommeren, 2000; van Ommeren, Rietveld, \& Nijkamp, 1998, 1999). Deding and her collaborators (2009) find that an increase in the distance between workplaces decreases the probability of moving while increasing the probability of changing jobs.

The use of angles has also been used to analyze issues around the spatial configuration of two-worker households and jobs. The use of angles has been most often used in understanding residential relocation (Adams, 1969; Clark et al., 2003; van Ommeren, 2000; van Ommeren et al., 1998, 1999). The angle most frequently encountered both for one-worker households (Madden, 1981; Simpson, 1987) as well as for two-worker households (Curran et al., 1982; Vandersmissen, Villeneuve, \& Thériault, 2003) is the angle (measured from the CBD) homeCBD-workplace (see Figure 1 (B)). The use of this angle is most appropriate in a monocentric city where it is generally faster to travel in the direction of the CBD than in any other direction. It should be noted that the notion that it is faster to travel towards the CBD is theoretical, and 
implies particular assumptions. Namely, that transport networks are designed to access the CBD and there are no important obstacles. For a good discussion of this, see Murphy(2012) sections 2 and 3 . In such cases, angles near $0^{\circ}$ are associated with more efficient home positioning since the closer the angle is to zero, the easier it will be (in terms of travel time) to get to work.

Other measures have been used in the context of non-monocentric cities. For example, van Ommeren (2000) and van Ommeren et al. (1998 and 1999) describe the positioning of twoworker households relative to their workplaces with the angle (measured at the location of the home) workplace 1 - home - workplace 2.

\begin{tabular}{|l|l|}
\hline Workplace 1 1 Workplace2 & \\
\hline (A) Work-to-work distance & (B) Home-CBD-workplace angle (theta) \\
\hline Figure 1: Basic relations between work and home location
\end{tabular}

Figure 2 provides some examples of workplace 1 - home - workplace 2 angles and gives a key to interpret them. Acute angles indicate that partners travel in similar directions (the extreme being $0^{\circ}$, exactly the same direction), while obtuse angles mean that the two workers commute in dissimilar directions (the extreme being $180^{\circ}$, totally opposite directions). Partners 
who travel in similar directions may experience benefits compared to other partners, as sharing part of the ride. At the regional level, a concentration of households where partners travel in relatively dissimilar directions could reveal the possibility to access many job centers or signify that these households live within a job centre. Inversely, if most households in a zone tend to go to work in a unique direction, it means that one or more job centers have an important attraction power on the workers living in this zone, or that this zone is poor in jobs.

This angle is considered a better measure of two-worker household workplace configuration because it links a household's constraints and choices with home to work distances. As well, the workplace 1 -home -workplace 2 angle illustrates whether or not two partners commute to work in the same direction (van Ommeren, 2000). Using the workplace 1 - home - workplace 2 angle is not only preferred to the home-CBD-workplace angle in a multi-centred city, it also compares favourably to work-work distance. 


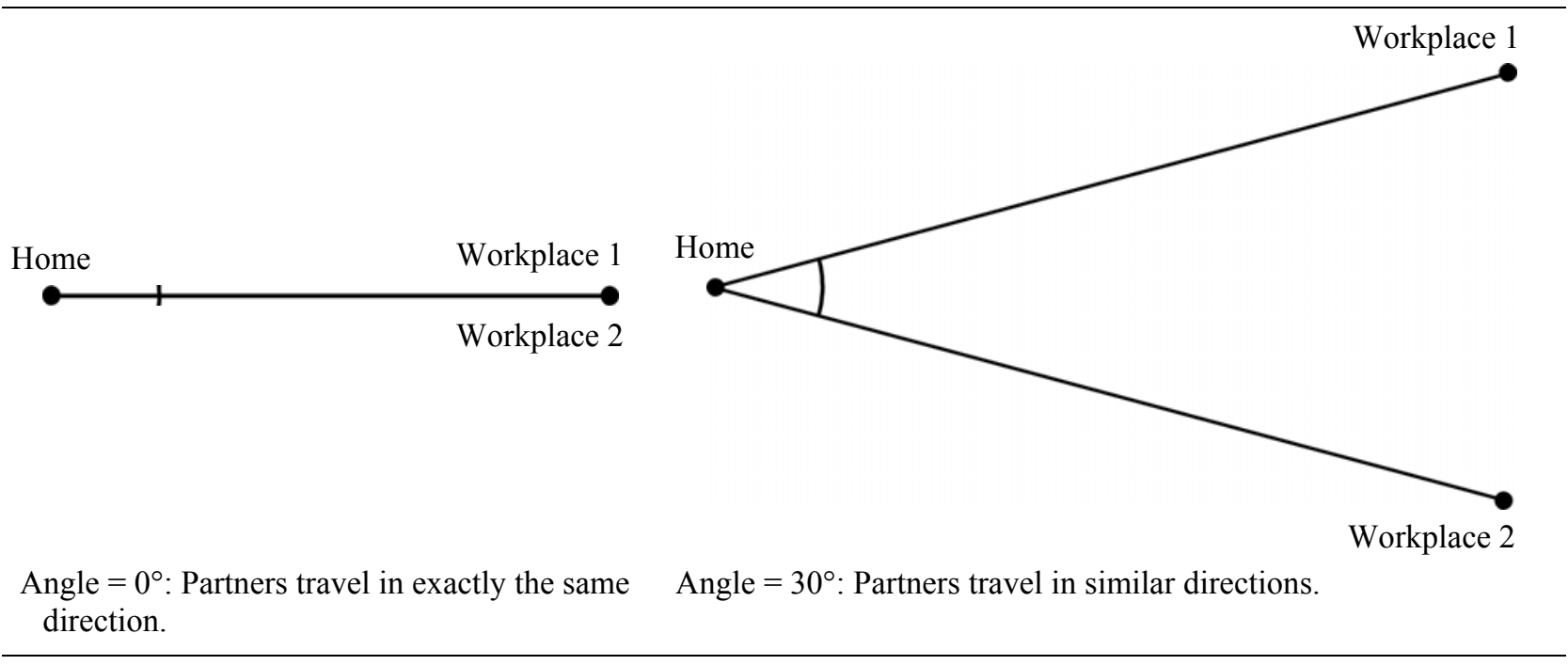

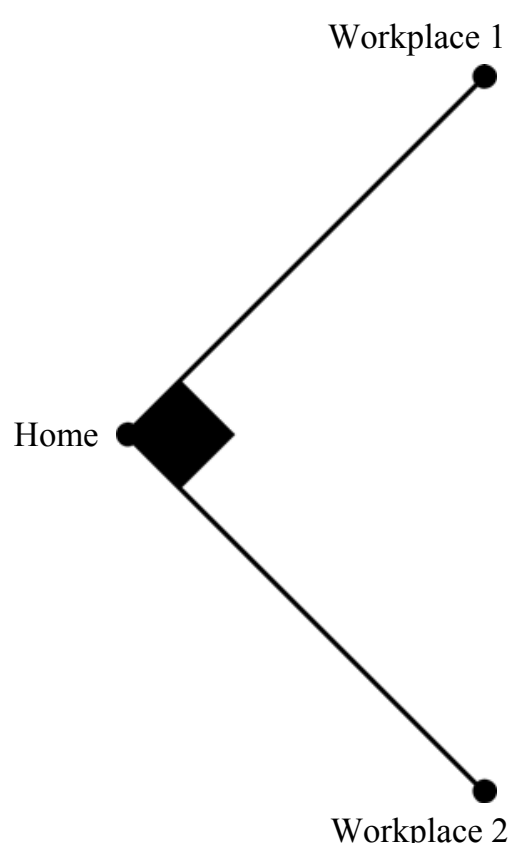

Angle $=90^{\circ}$ : Partners travel in directions as similar as dissimilar.

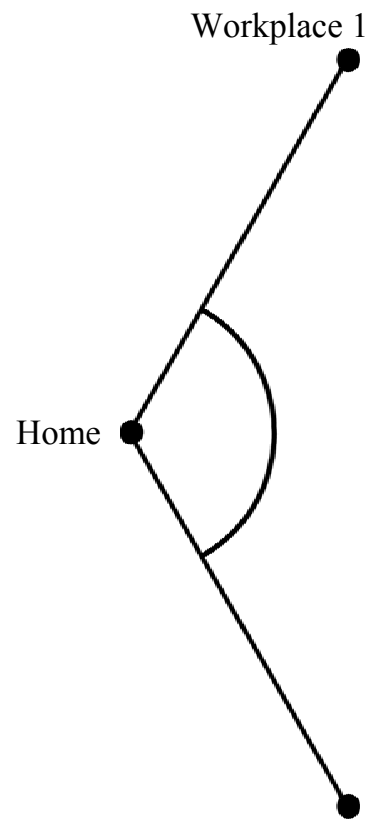

Workplace 2

Angle $=120^{\circ}:$ Partners travel in dissimilar directions .

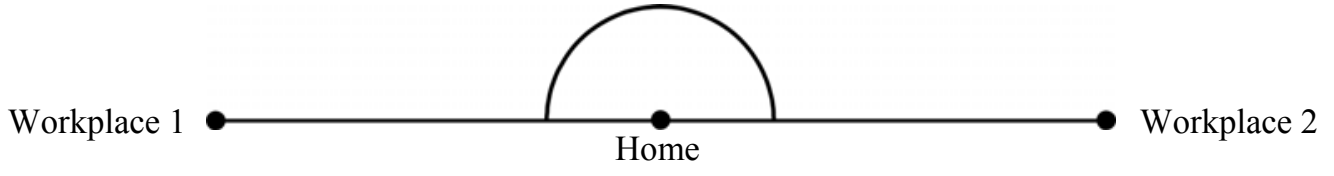

Angle $=180^{\circ}$ : Partners travel in totally opposite directions .

Figure 2 - Examples of workplace 1 - home - workplace 2 angles

First, households do not appear to directly consider work-work distances in their location choices (Deding et al., 2009; van Ommeren, 2000; van Ommeren et al., 1998, 1999). Second, the 
effect on home and job search behaviour of the work-work distance and of the workplace 1 home - workplace 2 angle are similar (van Ommeren, 2000). As a result, workplace 1 - homeworkplace 2 angle is a richer method to analyze workplace-household configuration than either home-CBD-workplace angle or workplace - workplace distance. It also appears to have the advantages work-to-work distance. At the same time, it has never been thought of as an explanatory factor in home-to-work distance, a methodological gap that this paper seeks to fill.

This paper contributes to the literature in a number of ways. Primarily, it uses a novel approach to quantify the degree to which partner commute distance affects individual commute distance, as well as to quantify the degree to which partners adjust their behaviour to reduce total commute distance. In so doing, it reconciles the previous findings of Kim (1995) and Sultana (2005) on one hand with those of Plaut (2006) on the other. It also provides empirical evidence that two-worker households do indeed adjust their residence workplace configuration to reduce commute distance, something sometimes questioned in the literature on excess commuting. Finally, it does so through the use of an adaptation of common approaches to analyzing commute distance (modeling total as well as individual commute distances) with variables inspired by the literature on household location and tenure.

\section{METHODOLOGY}

As discussed in the introduction and the literature review, this paper compares two- to one-worker household commute distances. It differs from previous research in two ways: first, by explicitly considering the effect of a partner's commute distance on individual commute distance; and second by evaluating how the spatial configuration of household and work locations affect total household commute distance. This is done in two analytical steps. 
In the first step, regression models (three altogether) of commute distance are estimated for individuals (all households combined, and one- and two-worker households separately). These models include typical control variables, as well as some less typical land use variables. The least typical variable, partner commute distance, is included in the two-worker household model. This makes it possible to evaluate the effect that a partner's distance has on commute distance. If partner commute distances are complements then partner commute distance will have a positive effect on individual commute distance. While allowing us to measure the effect of a partner's commute distance on an individual's commute distance, it does not allow us to understand whether there is a trade-off in commuting distances between partners.

In the second step, a regression model of total household commute distance is estimated. This is different from previous research on two-worker household commuting that has focused on individual commute distance, or average household commute distance. In addition to the different dependent variables, two unusual independent variables in addition to the typical control, and land-use variables are also used. These variables allow for a much richer understanding of household commuting and residence-workplace location dynamics. The two unusual variables used are: the difference between the longest and shortest Euclidean home to work distances in a household (longest-shortest distance), and the angle formed at home location by the arcs linking each workplace to home (i.e. workplace 1 - home - workplace 2 angle). Together, they describe the configuration of residence and workplaces.

The first variable, longest-shortest commute distance, is important because it illustrates to what extent total household commute distance is split between the two partners. The difference in distances should have a positive effect on the sum of distances. See Figure 3 for an example of this. 

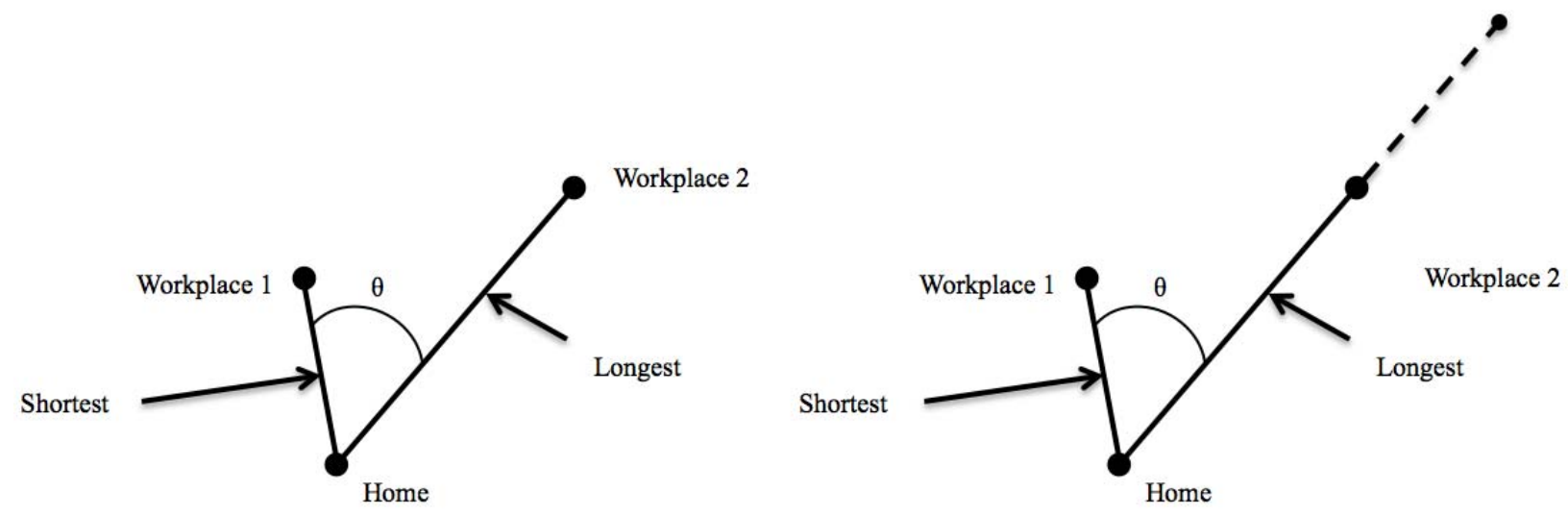

Figure 3 - Example of change in longest-shortest and total commute distance

The difference in distances is worth being analyzed because it provides us with a way to measure the degree to which partners trade-off commuting distance. If as longest-shortest commute distance increases, total commute distance increases, then we would be able to conclude that partner commute distances are complements. If as longest-shortestcommute distance increases, total commute distance does not increase or decreases, we would be able to conclude that partner commute distances are substitutes. If as longest-shortestcommute distance increases, total commute distance increases by less than one, we can conclude that partners trade off commuting distance to some extent. Some households may seek to achieve similar distances, while others might opt for one of the partners having the smallest distance possible. One can object that distance minimization may not be an issue in some households, but once controlling for the other main location factors, a general tendency towards minimization of distances (i.e. trading off of commute distance) should be observed. 
The second unusual variable is the workplace 1 - home - workplace 2 angle. In combination with longest-shortestdistance, this angle describes relative residence workplace configuration. The term relative residence workplace configuration is used because while the two variables together describe the configuration of residence and workplaces, they do not describe commute distances. For example, two families could share the same relative configuration (longest-shortest distance and the workplace 1 - home - workplace 2 angle), but not the same total commuting distance. Theoretically, there is no reason the workplace $1-$ home - workplace 2 angle should have any particular effect on total commute distance: a change in the residential workplace configuration of just the workplace 1 - home - workplace 2 angle would leave the arcs (commute distances) unchanged. At the same time, in residential location settings where employment opportunities can be found in different locations (i.e. not just the CBD), if households were to seek to reduce commuting distances, one would expect there to be a negative relationship between this angle and total commute distance - i.e. as the angle increases, commute distance should decrease. This pattern should continue until the workplace 1 - homeworkplace 2 angle is $180^{\circ}$ at which point the household would be located on an arc connecting the two work locations. It is at this point the combined commute distance would be at its minimum. Figure 4 provides an example to illustrate this phenomenon. The figure on the left represents a sample residence workplace configuration. Note that the workplace 1 - home workplace 2 angle is acute. In the figure on the right, the two workplaces are in the same relative position as the figure on the left - the home location has changed now so that it is on the arc connecting the two workplaces. As such the workplace 1 - home - workplace 2 angle is $180^{\circ}$ and the total length of commute distance is at its minimum. This variable was thus included in the model because it was believed to have an important impact on total commute distance, and in 
particular to test whether there were evidence that households adjust household location with respect to jobs so as to reduce commute distances.
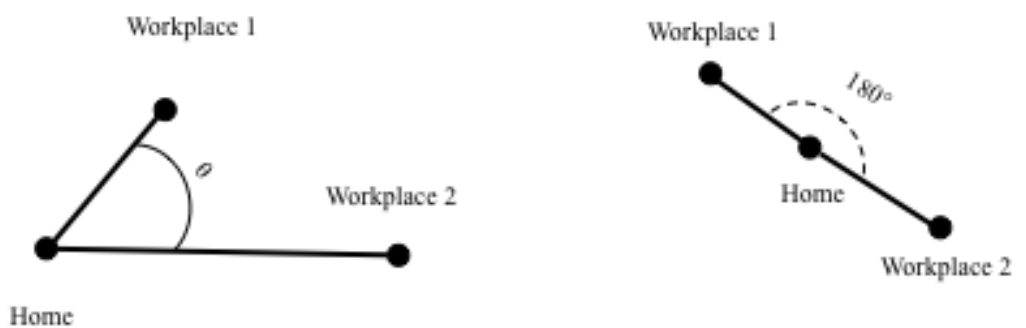

Figure 4: - Example of Workplace 1 - Home - Workplace 2 angle and commute distance

With this description of the principle features of the methodology, the next sections describe the case study region and the data used.

\section{CASE STUDY REGION}

The Montreal Metropolitan Community (CMM) includes 82 municipalities representing a combined population of 3.6 million people making it the second largest metropolitan area in Canada. Figure 5 shows the municipalities of the CMM and the municipalities included in the territory of the 2003 Origin-Destination (O-D) survey of the Agence Métropolitaine de Montréal (AMT), the regional public transportation planner (described below). The freeway network, as well as the five commuter train lines, and four metro lines are also shown. It can be seen that many transportation axes cross or end in the central business district. A particular geographic feature of the region is the presence of Mount Royal west of the CBD, an obstacle that can only be crossed by a collector road or with commuter train line. 

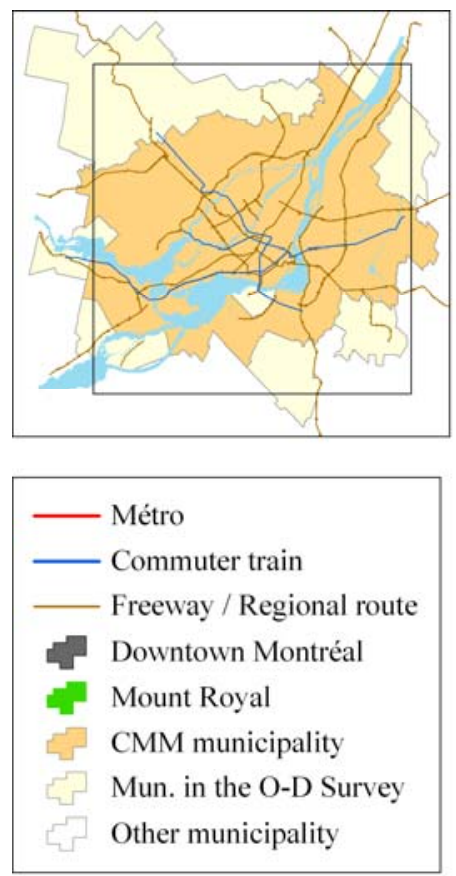

Data Sources: AMT, DMTI

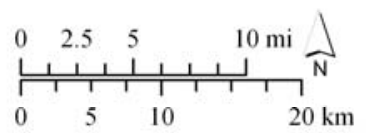

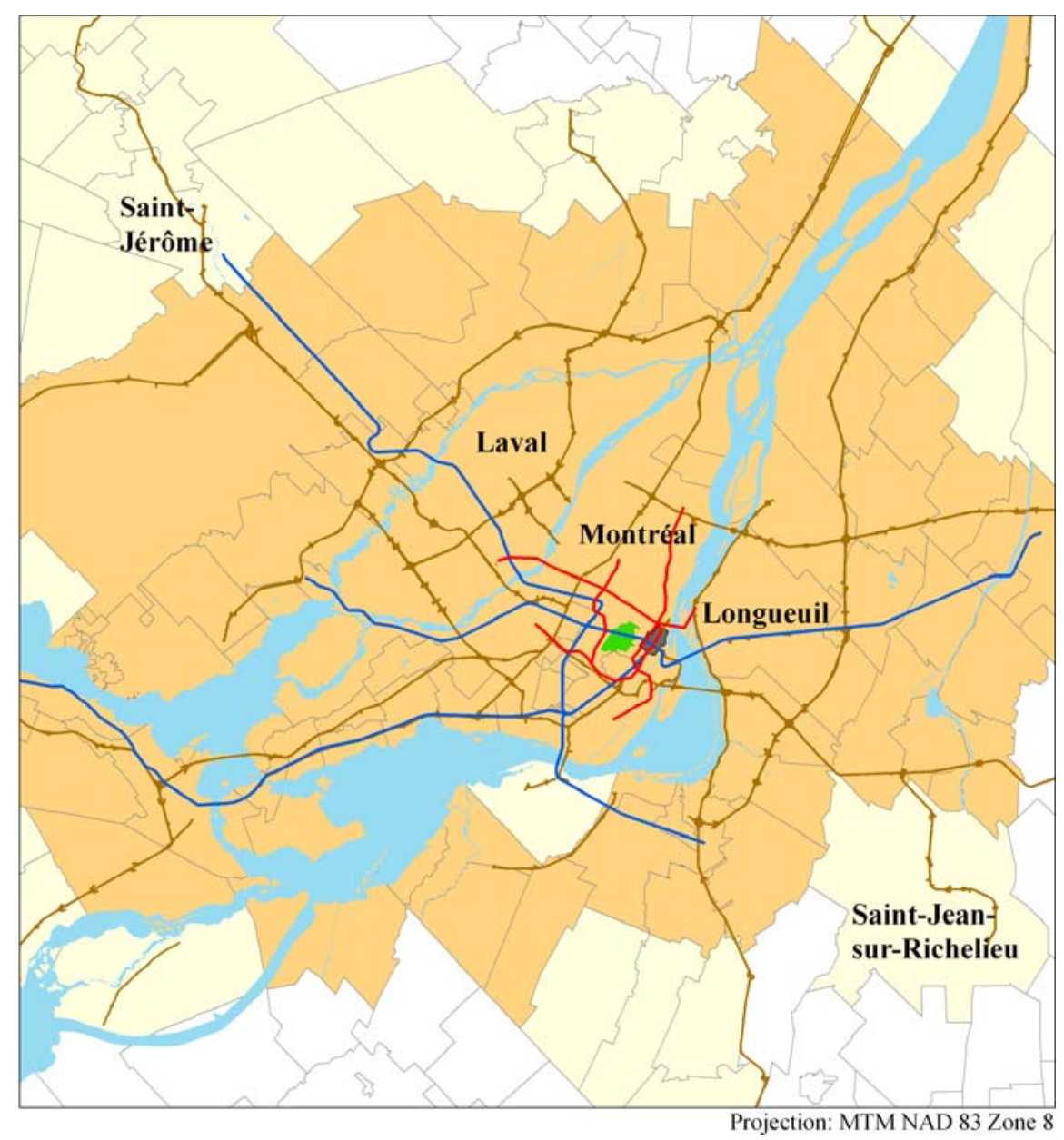

Figure 5: Geographic context of Montreal

In terms of demographic weight, the centre of the region is strong with 1.6 million people living in the city of Montreal. According to Coffey and Shearmur (2001), Montreal is a polycentric city, where six specialized employment centers exist other than the $\mathrm{CBD}$, although these centers are all located relatively close to the centre.

The primary data source for this research comes from the AMT 2003 Origin-Destination (O-D) survey (Agence métropolitaine de transport, 2003). The AMT O-D survey is a regular household survey conducted every five years. It collects detailed information on households (e.g. $\mathrm{x}, \mathrm{y}$ coordinates of households, number of members, number of cars, etc.), individuals (e.g. age, gender, employment status, etc.) and trips (x,y coordinates of origins and destinations, trip 
purpose, mode, transit lines used, bridges used, etc.). In 2003 it surveyed $4.7 \%$ of households $(59,959)$ in the Montreal metropolitan region (see territory on Figure , p. 18). Two-worker households were those with two adults, both of whom made work trips over the course of the day. One worker households were considered those where one adult made a work trip over the course of the day. Based on these definitions, 11,271 two-worker households and 20,725 oneworker household were identified for use in this analysis. At the time this research was done, the latest OD survey was that from 2003. During the review process, it was suggested that the Great Recession of 2007-2009 could have impacted on the nature of two-worker households and as a result on the validity of the data from the 2003 survey. If this were the case, it does not seem to hold, at least for Montreal. First, of all Canada was not affected by the Great Recession to the same extent as the US. The recession in Canada was milder as was the effect on unemployment. In fact, the unemployment rate in Montreal was lower in 2008 than it was in 2003. As well, the proportion of two-worker households remained steady between the two surveys ( $22 \%$ in 2003 and $21 \%$ in 2008).

In addition to the OD Survey, a few other data sources were used to calculate the variables used the analysis. Some variables (see below) require the use of network analysis performed in ArcGIS. The road network data used was DMTI Spatial's CanMap Streetfiles. Accessibility to jobs measures required information on employment location and congested origin destination travel times. Number of jobs by census tract was available from the 2001 Statistics Canada Census. Congested peak period automobile origin-destination travel times were provided by the Quebec ministry of transportation. 


\section{MODELING RESULTS}

As discussed in the methodology section, two sets of regressions were performed for this analysis. The first set is regression models of individual commute distance for all households in the sample, as well as for one-worker and two-worker households separately. The second is a regression of total household commute distance. In this section, the variables used in the regressions are described and summarized and then the results of the regression models are explained.

\section{Variables Used in Analysis}

A list of the dependent and independent variables used, as well as their definitions is found in Error! Reference source not found.. There are several variables that would ideally have been included in the analysis but were unfortunately not available from the OD survey. These included data on ownership and tenancy of home, years spent in the same home and job locations, previous household moves, home prices, length of marriage or union, type of job and level of education.

Of the variables used in the analysis, most of them are typical of regressions explaining commuting distance. Others involve a bit more discussion. The land-use variables require the most description apart from those of the last section of Table 1. Circuity (and household circuity) (Levinson \& El-Geneidy, 2009) is the ratio of network distance over Euclidean distance. As this ratio increases it implies a more circuitous route to work. As such, we would expect an increase in circuity to result in an increase in home to work distance. Both network distance and Euclidean distance were calculated with ArcGIS.

Accessibility to jobs (at home and at workplace) is calculated as the number of jobs that can be reached from a given point by car within 15 minutes. This is known as a cumulative 
opportunity accessibility measure. This was also calculated with ArcGIS based on employment data by census tract from Statistics Canada from the 2001 census. The concept of accessibility was initially developed by Hansen (1959) and has been used to explain home-to-work distances by Levinson (1998). Cumulative opportunity measures of accessibility are used here because they are similar to gravity measures for travel times under 30 minutes, while being easier to understand (El-Geneidy \& Levinson, 2006). Accessibility to jobs at home is expected to decrease commuting distances, while accessibility to jobs at workplace is expected to increase distances (Levinson, 1998). The reason why accessibility to jobs at workplace is expected to increase commuting distances is that a high concentration of jobs requires businesses to employ a labour force living relatively far away since residential purposes are outbid by commercial purposes and as a result there is a lack of housing stock.

A number of socio-demographic characteristics are also used in the model. The first is a dummy variable identifying the household as being a two-worker household. Despite protestations in the literature otherwise (e.g. (Giuliano \& Small, 1993), there is good empirical evidence to suggest (e.g. Sultana 2005) that two-worker households will commute the same or less than one-worker households. As such, one should not be surprised to find a negative correlation between the two-worker household variable and total home to work distance. There is a dummy variable indicating an individual as female. This is typically found to be negative in empirical research (Clark et al., 2003; Clark \& Wang, 2005; Gordon et al., 1989; Hanson \& Hanson, 1980; Johnston-Anumonwo, 1992; Madden, 1981; Singell \& Lillydahl, 1986; Sultana, 2005, 2006; M. J. White, 1977, 1986). There is no reason to expect it to be otherwise here. Age is typically found to be negative and there is no reason to expect otherwise here. The number of children is a variable for which there is different evidence in the literature and no a priori 
expectation of what it should be here. Income should have a positive effect on home to work distances based on previous research (Clark \& Wang, 2005; Madden, 1981; Turner \& Niemeier, 1997)

With respect to mode, we should expect that those traveling by car travel the furthest to work and others less. It is difficult to make definitive hypotheses about the actual ranking of the different modes a priori, although we should expect transit users to travel less and active modes even less than automobile users.

Apart from these more traditional variables, there are the three variables described in the methodology section that distinguish this research from that of others. These three variables are: the distance traveled by partner (individual commute distance models), the difference between the longest and shortest Euclidean home to work distances in a household, and the angle formed at home location by the direct lines linking each workplace to home (the latter two are used in the total commute distance regression).

As described in the methodology section, these variables will allow us to evaluate whether or not households trade-off commuting distance and adjust household configuration so as to reduce commute distance.

Table 1 - Definitions of the variables used in the regression models

\begin{tabular}{ll}
\hline Variable & Definition \\
\hline Dependent variables & \\
\hline $\begin{array}{l}\text { Home to work Euclidean distance } \\
\text { Sum of home to work Euclidean distances }\end{array}$ & $\begin{array}{c}\text { Home to work Euclidean distance in meters } \\
\text { Sum of home to work Euclidean distances in meters of a household }\end{array}$ \\
\hline Land use variables & $\begin{array}{c}\text { Home to work network distance divided by home to work Euclidean } \\
\text { distance (value is 1 or more) } \\
\text { In a household, sum of home to work network distances divided by the } \\
\text { sum of home to work Euclidean distances (value is 1 or more) }\end{array}$ \\
$\begin{array}{ll}\text { Combined circuity of the household } & \text { Number of jobs that can be reached by car within 15 minutes from } \\
\text { home/workplace, adjustment made for congestion }\end{array}$ \\
$\begin{array}{l}\text { Accessibility to jobs by car within } 15 \\
\text { minutes at home/workplace }\end{array}$ & Dummy variable that equals to 1 if the household has two workers and
\end{tabular}




\begin{tabular}{|c|c|}
\hline Variable & Definition \\
\hline Female & $\begin{array}{l}\text { zero if the household has one worker } \\
\text { Dummy variable that equals to } 1 \text { if the person is a female and zero if } \\
\text { the person is a male }\end{array}$ \\
\hline Age & Age of the person in years \\
\hline Mean age of the two workers & Average of the age of the two workers in years \\
\hline Number of children & Number of persons in the household that are 17 years old or less \\
\hline $\begin{array}{l}\text { Household income } \\
\qquad \begin{array}{l}{[\$ 0-\$ 20,000[} \\
{[\$ 20,000-\$ 40,000[} \\
{[\$ 40,000-\$ 60,000[} \\
{[\$ 60,000-\$ 80,000[} \\
{[\$ 80,000 \text { and above }}\end{array}\end{array}$ & $\begin{array}{l}\text { Dummy variables for the declared household income, before income } \\
\text { taxes }\end{array}$ \\
\hline \multicolumn{2}{|l|}{ Modal Characteristics } \\
\hline $\begin{array}{l}\text { Trip mode } \\
\text { Auto driver } \\
\text { Auto passenger } \\
\text { Public transit } \\
\text { Auto and transit } \\
\text { Other } \\
\end{array}$ & $\begin{array}{l}\text { Dummy variables for the trip mode declared by a person (other mostly } \\
\text { stands for walking, biking and taking a taxi) }\end{array}$ \\
\hline \multicolumn{2}{|l|}{ Variables Unique to this Research } \\
\hline Partner's home to work distance & $\begin{array}{l}\text { Home to work Euclidean distance in meters of the other member of } \\
\text { the household working }\end{array}$ \\
\hline $\begin{array}{l}\text { Difference between the longest and } \\
\text { shortest Euclidean home to work } \\
\text { distances }\end{array}$ & $\begin{array}{l}\text { In a household, the difference between the longest and shortest } \\
\text { Euclidean home to work distances }\end{array}$ \\
\hline Angle at home location & $\begin{array}{l}\text { Angle in degrees }\left(0^{\circ} \text { to } 180^{\circ}\right) \text { formed at home location by the direct } \\
\text { lines linking each workplace to home (workplace } 1 \text { - home - } \\
\text { workplace 2) }\end{array}$ \\
\hline
\end{tabular}

For the sake of making our hypotheses explicit, we use the strong hypothesis that the longest-shortest coefficient should be statistically insignificant. This implies that households perfectly trade-off commuting distance. In other words, a $1 \mathrm{~km}$ increase in longest-shortest distance should result in no increase in total commute distance. With respect to workplace1 home - workplace 2 angle, we assume that households on average will adjust their residenceworkplace configuration to reduce total commute distance. As a result, we expect the coefficient on this variable to be negative a priori.

With this description of the variables used in the various models, the next section provides summary statistics on the variables used. 


\section{Descriptive statistics}

Table 2 provides the descriptive statistics for the variables used in the regression models developed for the analysis separately for one- and two-worker households. As can be seen, oneand two-worker households are often similar, although some substantial differences stand out. Whereas circuity, age and the number of children are comparable in both types of households, Euclidean and network home to work distances are slightly longer in the two-worker ones. It is worth mentioning that this is different from what both Kim (1995) and Sultana (2005) found. Meanwhile, accessibility at both home and work locations is lower for workers in two-worker households. In terms of socio-demographic characteristics, two-worker households count as many women as men (only $43.3 \%$ of women in one-worker households), are more likely to have children and be wealthier. With respect to mode, they carpool almost twice as much as oneworker households, although they use public transit $25 \%$ less.

Table 2 - Descriptive statistics for the variables used in the regression models

\begin{tabular}{|c|c|c|c|c|c|c|}
\hline \multirow[b]{2}{*}{ Variable } & \multicolumn{3}{|c|}{$\begin{array}{l}\text { Workers in one-worker } \\
\text { households }\end{array}$} & \multicolumn{3}{|c|}{$\begin{array}{l}\text { Workers in two-worker } \\
\text { households }\end{array}$} \\
\hline & Median & Mean & Std. dev. & Median & Mean & Std. dev. \\
\hline Home to work Euclidean distance (m) & 8,533 & 11,445 & 10,282 & 9,702 & 12,304 & 10,328 \\
\hline Male & 9,628 & 12,536 & 10,833 & 10,842 & 13,352 & 10,722 \\
\hline Female & 7,342 & 10,017 & 9,323 & 8,617 & 11,226 & 9,791 \\
\hline $\begin{array}{l}\text { Sum of home to work Euclidean } \\
\text { distances }(\mathrm{m})\end{array}$ & & & & 21,061 & 24,609 & 16,921 \\
\hline Home to work network distance (m) & 11,019 & 14,309 & 12,199 & 12,546 & 15,404 & 12,259 \\
\hline Circuity & 1.2551 & 1.2935 & 0.2324 & 1.2574 & 1.3021 & 0.2742 \\
\hline Combined circuity of the household & & & & 1.2577 & 1.2857 & 0.1653 \\
\hline Age & 42 & 42 & 11 & 41 & 41 & 10 \\
\hline Number of children (if any) & 2 & 1.74 & 0.83 & 2 & 1.72 & 0.74 \\
\hline Accessibility to jobs at home & 62,515 & 104,071 & 106,597 & 45,083 & 84,638 & 94,685 \\
\hline Accessibility to jobs at workplace & 167,051 & 199,015 & 157,425 & 156,859 & 194,307 & 156,285 \\
\hline Male & 167,598 & 199,034 & 155,448 & 154,661 & 193,264 & 152,781 \\
\hline Female & 179,150 & 210,785 & 162,166 & 156,951 & 195,376 & 159,797 \\
\hline $\begin{array}{l}\text { Difference between the longest and } \\
\text { shortest distances }(\mathrm{m})\end{array}$ & & & & 4,814 & 7,722 & 8,985 \\
\hline Angle at home location $\left(^{\circ}\right)$ & & & & 34.2 & 52.8 & 52.7 \\
\hline
\end{tabular}




\begin{tabular}{lcc}
\hline Variable & Proportion & Proportion \\
\hline Female & $43.3 \%$ & $49.3 \%$ \\
Presence of at least one child & $36.2 \%$ & $46.1 \%$ \\
Household income & & \\
$\quad \$ 0-\$ 20,000[$ & $10.1 \%$ & $2.8 \%$ \\
{$[\$ 20,000-\$ 40,000[$} & $31.8 \%$ & $15.3 \%$ \\
{$[\$ 40,000-\$ 60,000[$} & $26.4 \%$ & $24.7 \%$ \\
{$[\$ 60,000-\$ 80,000[$} & $14.8 \%$ & $23.2 \%$ \\
{$[\$ 80,000$ and above } & $16.9 \%$ & $34.1 \%$ \\
Trip mode & & \\
Auto driver & $68.1 \%$ & $70.9 \%$ \\
Auto passenger & $4.4 \%$ & $7.5 \%$ \\
Public transit & $18.6 \%$ & $14.0 \%$ \\
Auto and transit & $2.6 \%$ & $3.1 \%$ \\
Other & $6.3 \%$ & $4.5 \%$ \\
Trip mode (male) & & \\
Auto driver & $74.9 \%$ & $78.4 \%$ \\
Auto passenger & $2.9 \%$ & $3.9 \%$ \\
Public transit & $14.7 \%$ & $11.4 \%$ \\
Auto and transit & $1.9 \%$ & $2.3 \%$ \\
Other & $5.6 \%$ & $4.0 \%$ \\
Trip mode (female) & & \\
Auto driver & $59.3 \%$ & $63.0 \%$ \\
Auto passenger & $6.3 \%$ & $11.2 \%$ \\
Public transit & $23.7 \%$ & $16.7 \%$ \\
Auto and transit & $3.4 \%$ & $4.0 \%$ \\
Other & $7.2 \%$ & $5.0 \%$ \\
\hline $\mathrm{N}$ & 20,725 & 22,542 \\
\hline
\end{tabular}

In both types of households, men and women benefit from very similar levels of accessibility at workplace, yet they do not use the same modes in the same proportions for their trips. Females are less likely to drive a car, but they are more likely to be a car passenger or to take public transit. Members of two-worker households show a median difference in the distances that they travel equal to $4.8 \mathrm{~km}$. Finally, the median workplace 1 - home - workplace 2 angle is $34.2^{\circ}$, an aspect developed further below. In addition to these descriptive statistics, understanding some of the variables is facilitated by graphical and cartographical presentation.

Figure 6 maps a cumulative opportunity measure of accessibility to jobs by car for a (congested) travel time of 15 minutes. The highest accessibility levels are reached in or around 
the CBD and generally, these levels decrease with the distance from the CBD. This decrease is less pronounced along freeways and regional routes, which provide more access to jobs, and west of the CBD, since the Ville Saint-Laurent/Dorval and Marché Central job centers offer many job opportunities (Shearmur, 2006). Although it is true that people may be willing to drive more than 15 minutes to access their jobs, a travel time of 15 minutes allows for a

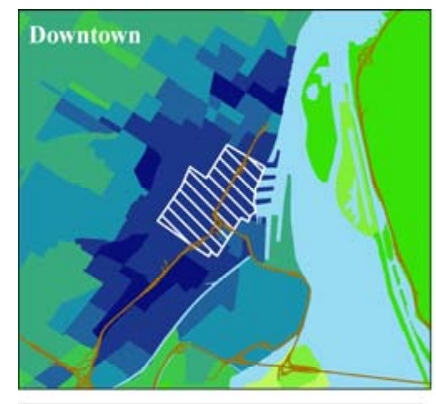

Freeway / Regional route Accessiblity to jobs by car within 15 minutes $1-20,000$

$20,001-40,000$

$4 \quad 40,001-80,000$

- $80,001-125,000$

푸 $125,001-175,000$

푸 $\quad 175,001-250,000$

두 250,001-325,000

드 $325,001-400,000$

두 400,001- 500,000

$500,001-600,000$

Data Sources: AMT, Dun \& Bradstreet, Statistics Canada

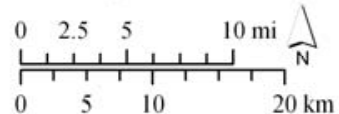

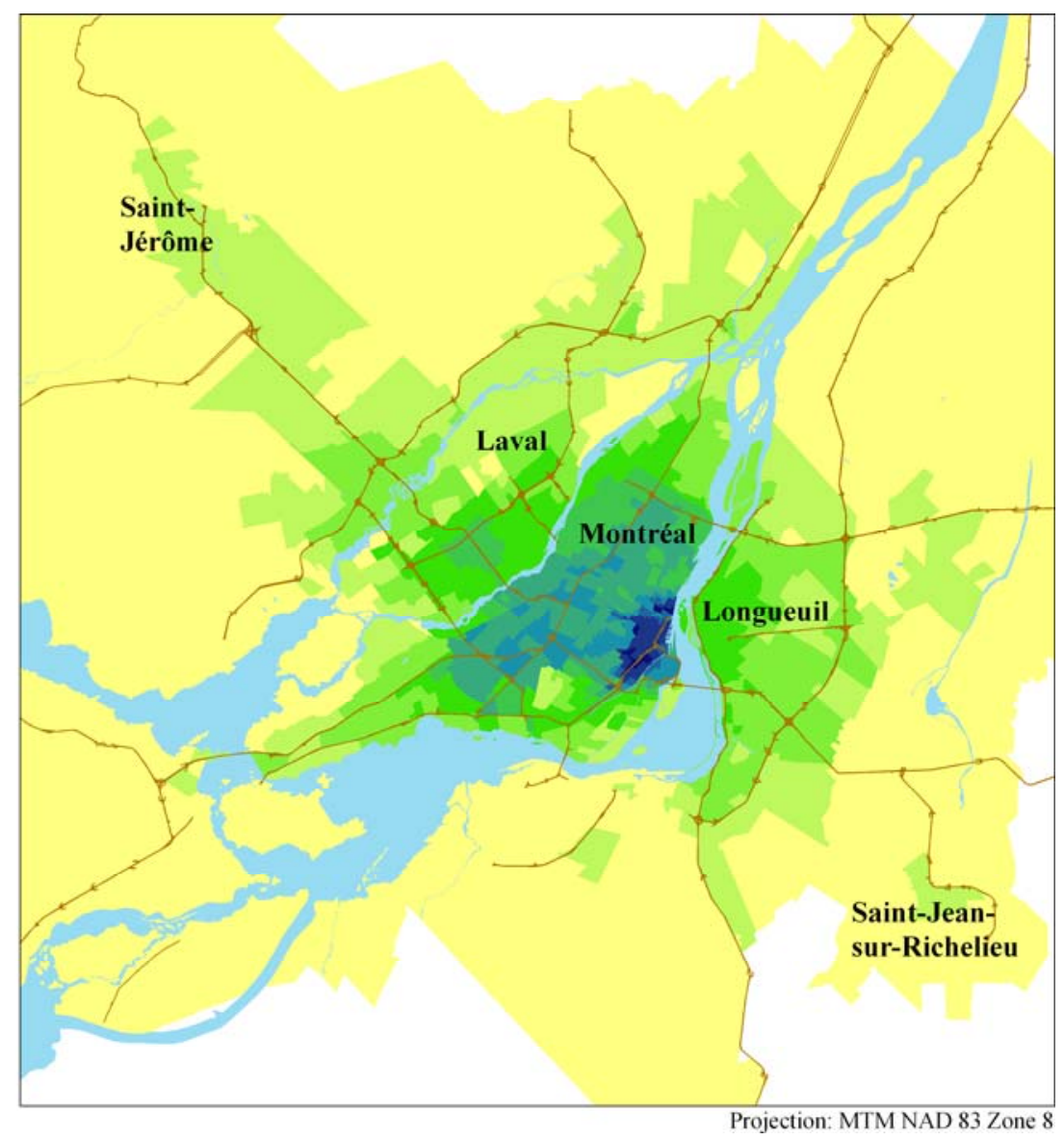

characterization of zones that relies more on local attributes than on regional attributes.

Figure 6: Accessibility to jobs within 15 minutes by car

The frequency distribution of workplace 1 - home - workplace 2 angles is illustrated in Figure 7. It would be a bell-shaped curve if negative angles were allowed. The predominance of acute angles shows that the members of the same household tend to go in the same direction to 
work. In fact, $76 \%$ of angles are below $90^{\circ}$, which is similar to the Netherlands' proportion of 85\% (van Ommeren, 2000). It confirms that households do not locate their home on the direct line that could be traced between their two workplaces, even though it may be an intuitive choice.

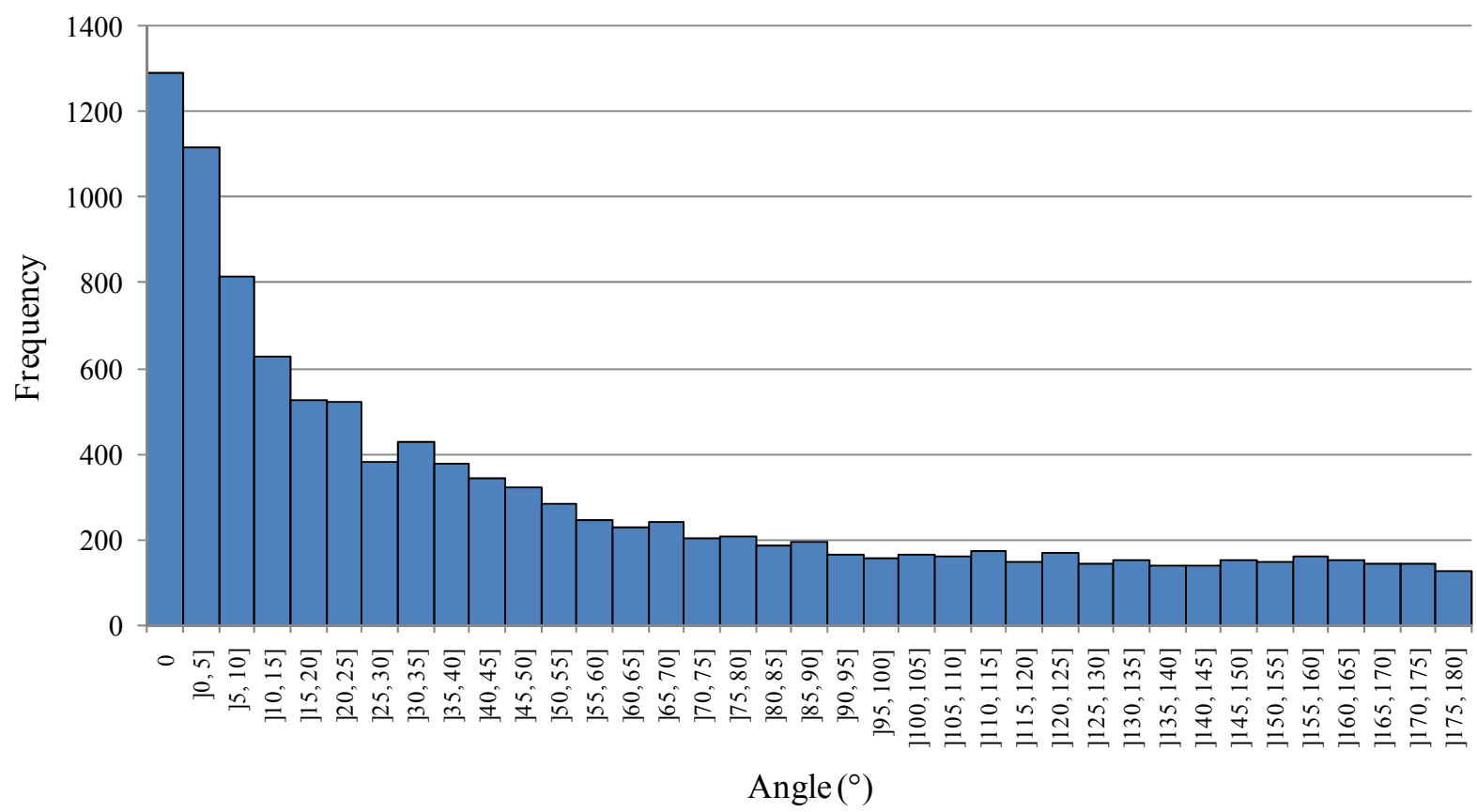

Figure 7: Frequency of workplace 1 - home - workplace 2 angle

In addition to showing a frequency distribution of workplace 1 - home - workplace 2 angle, it is also instructive to consider the spatial distribution of this angle. Error! Reference source not found. is a cluster and outlier analysis of the workplace 1 - home-workplace 2 angle that reveals clusters of high or low values, as well as outliers of high or low values surrounded by clusters of opposite values. Anselin Local Moran's I statistic for spatial autocorrelation calculates spatial correlation by taking into account the values of features and their location relative to each other. In the case of angles, the higher the value, the more 
dissimilar are the directions that partners take to reach their jobs. Clusters of high values are concentrated in the central part of the Island of Montreal, extending to Longueuil and Laval, and in Saint-Jérôme and Saint-Jean-sur-Richelieu, while clusters of low values are frequent around the centre of the Island of Montreal, stretching along the Saint Lawrence River. Where clusters of high values are encountered, large angles show that people can find work in any direction from home, which can mean that land use is diversified and that transportation networks are efficient. On the contrary, low-value clusters indicate that the members of a household reach their jobs going in the same direction, being constrained by their environment. This pattern of high- and low-value clusters concerns $29.7 \%$ of households. It could be explained by the high number of jobs available in the centre of the region and by high job accessibility by any mode for houses located in the centre. Unlike in other suburbs, Saint-Jérôme and Saint-Jean-sur-Richelieu exhibit clusters of high values, which could be due to the fact that these cities still act as local centers and are not dependent on jobs found on the Island of Montreal. 

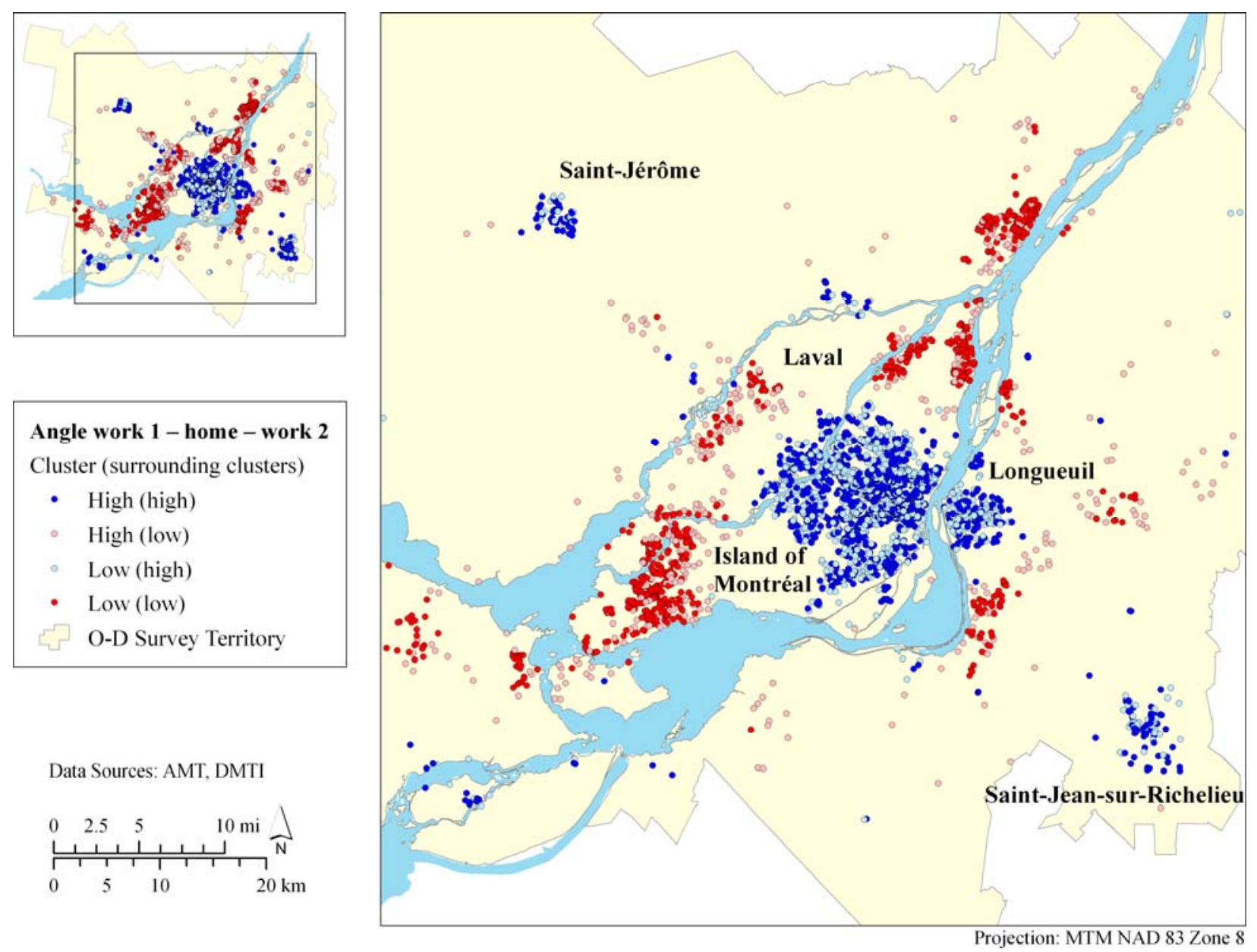

Data Sources: AMT, DMTI

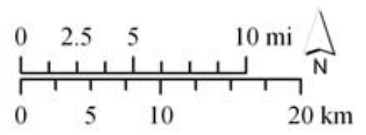

Angle work 1 - home - work 2

Cluster (surrounding clusters)

- High (high)

- High (low)

- Low (high)

- Low (low)

O-D Survey Territory

Figure 8: High- and low-value clusters and outliers of the workplace 1 - home - workplace 2 angle

\section{Statistical models}

In the O-D survey sample, frequencies of distances travelled decrease exponentially as distances increase in length. Therefore, the dependent variables (commute distance variables) are logarithmically transformed. The first three regression models' dependent variable is the natural logarithm of individual commute distance for: workers in all households in the sample (Model 1), workers in one-worker households (Model 2), and workers in two-worker households (Model 3). The last model (Model 4) uses the natural logarithm of the sum of commute distance in twoworker households as its dependent variable. The choice to use Euclidean distance instead of network distance is explained by the inclusion of the workplace 1 - home - workplace 2 angle 
variable in Model 4. It can only be calculated using Euclidean distances and since we wanted to ensure comparability with all the models, the Euclidean distance was used for the others as well. To control for the difference between Euclidean and network distances, the circuity variable is included in all regressions. In order to keep a more representative sample in regression Model 4, differences between the longest and shortest home to work Euclidean distances that were equal to 0 and workplace 1 - home -workplace 2 angles between 0 and 1 were all changed to a value of 1 prior to the logarithmic transformation of the variable. In addition, Model 4 only includes two-worker households formed of a man and a woman, as trip mode and accessibility to jobs at workplace were gendered. This choice represents a loss of $8 \%$ of cases.

\section{Models of Individual Commute Distance}

The first three logarithmic regression models concern commute distance of workers living in one- or two-worker households and are detailed in Table 3. Standard errors in the three models are robust to heteroskedasticity and there is no multicollinearity in any of them. Concerning the coefficients, one should first note that the observed signs are consistent with the previous literature and a priori hypotheses about them, females travelling less than males (Clark et al., 2003; Clark \& Wang, 2005; Gordon et al., 1989; Hanson \& Hanson, 1980; JohnstonAnumonwo, 1992; Madden, 1981; Singell \& Lillydahl, 1986; Sultana, 2005, 2006; M. J. White, 1977, 1986), income increasing distances (Clark \& Wang, 2005; Madden, 1981; Turner \& Niemeier, 1997), accessibility to jobs at home decreasing distances, and accessibility to jobs at workplace increasing distances (Levinson, 1998). As for the number of children, it does not seem to have an effect on distances. This is not of concern since empirically the effect has not been consistent: some have found it to be positive (Mok, 2007) while others have found it to be negative (Singell \& Lillydahl, 1986). More complicated effects have also been observed, such as different effects for men and women (Madden, 1981; Singell \& Lillydahl, 1986; M. J. White, 
1986). When circuity increases, total commute distance decreases, as expected. Age has a small negative effect on distance. In terms of transport modes, the omitted modal category is driving a car. Car passengers and public transit users travel shorter distances than car drivers, while people who use a car before taking public transit display the longest commute distances. The latter combination is probably representative of suburban workers driving to park-and-ride facilities to take commuter trains or bus shuttles to downtown. A perhaps surprising observation is that transit users travel slightly longer distances than auto passengers, especially in one-worker households. However, it is unclear to what extent these two alternatives compete and if drivers with passengers also travel shorter distances. 
Table 3 - Models 1 - 3: Individual commute distance

\begin{tabular}{|c|c|c|c|c|c|c|c|c|c|}
\hline & \multicolumn{3}{|c|}{$\begin{array}{l}\text { (1) Workers in one- or two- } \\
\text { worker households }\end{array}$} & \multicolumn{3}{|c|}{$\begin{array}{l}\text { (2) Workers in one-worker } \\
\text { households }\end{array}$} & \multicolumn{3}{|c|}{$\begin{array}{l}\text { (3) Workers in two-worker } \\
\text { households }\end{array}$} \\
\hline & Coefficient & $\mathrm{t}$ & $\beta$ & Coefficient & $\mathrm{t}$ & $\beta$ & Coefficient & $\mathrm{t}$ & $\beta$ \\
\hline Constant & 9.98607 & $128.26 * * *$ & & 10.24753 & $88.57 * * *$ & & 7.97242 & $59.30 * * *$ & \\
\hline Ln of circuity & -1.15845 & $-28.74 * * *$ & -0.15434 & -1.17362 & $-19.50 * * *$ & -0.14838 & -1.13509 & $-21.54 * * *$ & -0.15872 \\
\hline Female & -0.18619 & $-19.48 * * *$ & & -0.17639 & $-12.41 * * *$ & & -0.22929 & $-17.80 * * *$ & \\
\hline Age & -0.00393 & $-8.48 * * *$ & -0.03879 & -0.00367 & $-5.62 * * *$ & -0.03768 & -0.00334 & $-5.15 * * *$ & -0.03156 \\
\hline Number of children & -0.00591 & -1.22 & -0.00545 & 0.00740 & 1.03 & 0.00664 & -0.01535 & $-2.35 *$ & -0.01444 \\
\hline \multicolumn{10}{|l|}{ Household income } \\
\hline$[\$ 0-\$ 20,000[$ & -0.24593 & $-10.45 * * *$ & & -0.28847 & $-10.18 * * *$ & & -0.10336 & $-2.38 *$ & \\
\hline$[\$ 20,000-\$ 40,000[$ & -0.08079 & $-5.74 * * *$ & & -0.08771 & $-4.78 * * *$ & & -0.06647 & $-3.04 * *$ & \\
\hline$[\$ 60,000-\$ 80,000[$ & 0.08298 & $6.01 * * *$ & & 0.05182 & $2.42 *$ & & 0.07969 & $4.42 * * *$ & \\
\hline$[\$ 80,000$ and above & 0.10223 & $7.89 * * *$ & & 0.06837 & $3.37 * *$ & & 0.08263 & $4.92 * * *$ & \\
\hline \multicolumn{10}{|l|}{ Trip mode } \\
\hline Auto passenger & -0.23034 & $-10.64 * * *$ & & -0.30503 & $-7.83 * * *$ & & -0.18934 & $-7.78 * * *$ & \\
\hline Public transit & -0.17961 & $-14.47 * * *$ & & -0.16008 & $-9.08 * * *$ & & -0.17733 & $-10.28 * * *$ & \\
\hline Auto and transit & 0.20844 & $13.52 * * *$ & & 0.25728 & $10.99 * * *$ & & 0.16218 & $7.88 * * *$ & \\
\hline Other & -1.69752 & $-62.65 * * *$ & & -1.65645 & $-44.88 * * *$ & & -1.68607 & $-42.33 * * *$ & \\
\hline \multicolumn{10}{|l|}{$L n$ of accessibility to jobs } \\
\hline At home & -0.30567 & $-70.52 * * *$ & -0.37024 & -0.30019 & $-47.60 * * *$ & -0.36192 & -0.26858 & $-43.17 * * *$ & -0.32512 \\
\hline At workplace & 0.24927 & $39.88 * * *$ & 0.27538 & 0.22126 & $23.84 * * *$ & 0.23784 & 0.26103 & $31.47 * * *$ & 0.29609 \\
\hline Two-worker household & -0.02067 & $-2.09 *$ & & & & & & & \\
\hline \multirow{3}{*}{$\begin{array}{l}\text { Ln of partner's home to } \\
\text { work distance }\end{array}$} & & & & & & & 0.16208 & $20.84 * * *$ & 0.16591 \\
\hline & $\mathrm{N}$ & 34,589 & & $\mathrm{~N}$ & 16,517 & & $\mathrm{~N}$ & 18,070 & \\
\hline & $\mathrm{R}^{2}$ & 0.3568 & & $\mathrm{R}^{2}$ & 0.3590 & & $\mathrm{R}^{2}$ & 0.3778 & \\
\hline
\end{tabular}


Compared to one-worker households, two-worker households benefit on average from $18.7 \%$ less accessibility to jobs at home. Yet, according to regression models 1 to 3 , members of two-worker households are less sensitive to accessibility to jobs at home (a factor that has a negative effect on distance) and more sensitive to accessibility to jobs at workplace (a factor that has a positive effect on distance) than members of one-worker households.

The results reported until here have been for primarily control variables. With respect to this research, two variables are particularly pertinent: the two-worker household dummy in Model 1, and partner commute distance in Model 3. With respect to the former, the coefficient for the two-worker household dummy implies that each member of a two-worker household commutes on average $2.07 \%$ less than a worker in a one-worker household. This result is worth highlighting. As was mentioned in the section on descriptive statistics, without controlling for other variables, average commute distance in two-worker families in Montreal is longer than for one-worker families - a finding that is different than what others (e.g. Kim (1995) and Sultana (2005) have found. At the same time, it is interesting to note that when other factors are controlled for, we also find that members of two-worker households travel less members of oneworker households.

The other particularly pertinent variable in these models is the logarithm of partner commute distance. It is interesting because this variable is our first proper and direct test of Plaut's (2006) claim that partner commute distances are complements and substitutes of one another. The coefficient itself (since it, as well as the dependent variable are logarithmic) implies that an individual's commute distance increase by $0.16 \%$ for every $1 \%$ increase in partner commute distance. As such, this coefficient supports the claim that partner commute distances 
are indeed complementary. Plaut's second claim that "Spouses do not appear to be trading off one's commuting distance/time for the other's" cannot be tested here, will be in Model 4.

\section{Total Two-worker Household Commute Distance Model}

The last model (presented in Table 4) concerns the sum of home to work Euclidean distances in two-worker households. Compared to Model 3, this model has: a different dependent variable, the logarithm of partner distance has been removed, the two "residence - workplace configuration" variables (see section "Variables Used in Analysis," above) have been included, and several of the variables have been allowed vary by gender. Standard errors in Model 4 are robust to heteroskedasticity and the model does not suffer from multicollinearity.

Table 4 - Total commute distance model (two-worker households only)

\begin{tabular}{|c|c|c|c|}
\hline & Coefficient & $\mathrm{t}$ & $\beta$ \\
\hline Constant & 10.36759 & $72.31 * * *$ & \\
\hline Ln of combined circuity of the household & -0.94103 & $-12.38 * * *$ & -0.13459 \\
\hline Mean age of the two workers & -0.00408 & $-5.42 * * *$ & -0.04763 \\
\hline Number of children & -0.01058 & -1.59 & -0.01338 \\
\hline \multicolumn{4}{|l|}{ Household income } \\
\hline$[\$ 0-\$ 20,000[$ & -0.16189 & $-3.11 * *$ & \\
\hline$[\$ 20,000-\$ 40,000[$ & -0.07315 & $-3.08 * *$ & \\
\hline$[\$ 60,000-\$ 80,000[$ & 0.08201 & $4.44 * * *$ & \\
\hline$[\$ 80,000$ and above & 0.09724 & $5.45 * * *$ & \\
\hline Ln of accessibility to jobs at home & -0.26017 & $-35.05 * * *$ & -0.41687 \\
\hline \multicolumn{4}{|l|}{ MALE CHARACTERISTICS } \\
\hline \multicolumn{4}{|l|}{ Trip mode } \\
\hline Auto passenger & -0.10419 & $-2.63 * *$ & \\
\hline Public transit & -0.13868 & $-6.52 * * *$ & \\
\hline Auto and transit & 0.04621 & 1.46 & \\
\hline Other & -0.69698 & $-16.28 * * *$ & \\
\hline Ln of accessibility to jobs at workplace & 0.07212 & $9.15 * * *$ & 0.10512 \\
\hline \multicolumn{4}{|l|}{ FEMALE CHARACTERISTICS } \\
\hline \multicolumn{4}{|l|}{ Trip mode } \\
\hline Auto passenger & -0.03906 & -1.51 & \\
\hline Public transit & -0.08510 & $-4.56 * * *$ & \\
\hline Auto and transit & 0.08350 & $3.61 * * *$ & \\
\hline Other & -0.62826 & $-15.73 * * *$ & \\
\hline$L n$ of accessibility to jobs at workplace & 0.11583 & $14.63 * * *$ & 0.18104 \\
\hline Ln of shortest--longest distance & 0.10018 & $25.58 * * *$ & 0.36147 \\
\hline \multirow[t]{3}{*}{ Ln of angle at home location } & -0.07599 & $-12.73 * * *$ & -0.15886 \\
\hline & \multirow{2}{*}{\multicolumn{2}{|c|}{$\begin{array}{l}8,231 \\
04389\end{array}$}} & \\
\hline & & & \\
\hline
\end{tabular}

*** Significant at 99.9\%

** Significant at 99\% 
Comparing Model 3 to Model 4, circuity, age, number of children, and household income have effects of similar magnitude on commute distances. As expected, the $\beta$ standardized coefficient of accessibility to jobs at home is larger in Model 4 than in Model 3. Indeed, the Model 4 estimates the sum of the two distances in a household, both of which are being affected by the same accessibility to jobs at home. That accessibility to jobs at home play a larger role in the sum of distances model than in the individual distances model may be an indicator that distances are at least partially pooled in a household.

The gendered variables in Model 4 are: the trip mode dummies and accessibility to jobs at workplace. Concerning trip mode, the base scenario in Model 4 is that the two partners drive (separate) cars to commute. When somebody uses a mode other than driving a car, the sum of distances decreases more (or increases less) if it is a male who does not drive than if it is a female. While men travel longer distances than women to go to work - which is documented and expected - they seem willing to pay a premium in distance to drive a car and not use another mode. It may be because they prefer to drive or because their job locations are less accessible by other modes - Shearmur (2006) showed that contrary to women, men travel longer distances to every suburban job centre than to the CBD. The second gendered variable is accessibility to jobs at workplace. This time, women could be willing (or constrained) to travel more than men for the same increase in accessibility to jobs at workplace, as the sum of distances is more affected by women's accessibility to jobs at workplace. This finding is consistent with Shearmur (2006), who noted that women travel more than men to reach jobs in the CBD, and the CBD displays the highest levels of accessibility to jobs in the region (see Figure 6). 
The first residence workplace configuration variable is longest-shortest total commute distance. Its coefficient implies that increasing longest-shortest difference by $1 \%$ increases total commute distance by $0.10 \%$. Since this coefficient is positive, a decrease in the difference has to be caused primarily by a decrease in the longest distance. Yet, as the decrease in the difference does not yield a unitary change in the sum of distances, the decrease in the longest distance must be partly compensated by an increase in the shortest distance. Likewise, an increase in the difference would be caused by an increase in the longest distance and amplified by a smaller decrease in the shortest distance. The global effect of an increase in the difference in distances would be a smaller increase in the sum of distances. Hence, the difference between the longest and the shortest distances effect highlights that in the long run or on a large scale, partners living in two-worker households adjust their commute distances to each other's distance. As was the case with the partner distance variable in Model 3, this result suggests that partner trip distance is a complement, but that this relationship is inelastic, suggesting that households do trade-off commuting distance. As such, our a priori hypothesis that partner distance should have no effect on total commute distance is wrong. It is also noteworthy that two-worker households in the dataset, are not necessarily people who are in relationships, or partners since we have no information on this. Despite this, we find this positive but inelastic result. We can only assume that were it possible to include only two-worker households where the two workers were in relationships, that our results would be even stronger - i.e. more inelastic.

The second residence workplace configuration variable is the logarithm of workplace 1 home - workplace 2 angle. The coefficient for this variable is -0.076 , implying that total commute distance decreases by $0.076 \%$ for a $1 \%$-increase in the angle. This corresponds to a $\beta$ standardized coefficient of -0.16 for one standard deviation in angle. Its sign confirms our 
hypothesis that an increase in the angle should decrease total commute distance. As such, it also suggests that households will adjust their residence workplace configuration in order to reduce total commute distance.

Taken together, the significance of spatial interrelationship factors suggest that despite facing more constraints than one-worker households (Costa \& Kahn, 2000; Green, 1997; Sultana, 2005; van Ommeren, 2000), two-worker-household members may shrink their commuting distances by applying strategies that involve adjusting their home to work commuting trips to one another's.

\section{DISCUSSION AND CONCLUSION}

This research has concentrated on the commuting distance of two-worker households. In the transportation and land-use literature, it has generally been assumed that since two-worker households are faced with more constraints (two job locations instead of one) on where to locate, that they should commute further than one-worker households. Moreover, in discussions related to excess-commuting, it has been argued that employment location (and commute time minimization in particular) has a smaller impact on household than what people have traditionally believed - and that it has an even smaller impact on household location for twoworker families. While it is intuitive that two-worker families ought to travel more than oneworker families, the empirical research that has emerged to approach this question has not been decisive, and it is not at all clear that two-worker families do travel more than one worker families. The most pertinent empirical research (Kim, 1995; Sultana, 2005) has suggested that two-worker families commute about the same as (or even less than) one-worker families. Kim (1995) also finds two-worker households do not "excess-commute" much more than one-worker households and that employment location (and commute cost minimization) are more important 
in terms of household location than the excess-commuting literature would suggest. Plaut (2006) on the other hand concludes that spouses do not trade-off one's commuting distance for the other's - that a partner's commute distance is a "complement" and not a "substitute."

The first thing that was recognized in examining these conflicting findings was that Plaut (2006) over-interpreted her findings. Her analysis, using seemingly unrelated regression techniques was able to uncover positive correlation between the errors of commuting distance of couples in two-worker households. Her conclusion from this analysis is that commute distance is complementary between couples was valid. Where she overreached was in further concluding that this suggested that couples did not trade-off commuting distance.

The exploration of this literature and the results of the analysis presented here have allowed us to better understand the phenomenon, as well as to reconcile these seeming contradictions. This has been done through the use of regression models of individual and total commute distance for one- and two-worker households. In particular, unusual variables were included in these regressions that allowed us to test: explicitly whether partner commute distance is complementary; whether there is evidence that two-worker households trade-off commute distance; and finally, whether two-worker households adjust home location to reduce commuting distance.

Initial examination of the raw data showed that, on average, members of two-worker households travel more than those in one-worker households. This appeared to support the commonly held supposition present in the literature, while contradicting both Kim (1995) and Sultana (2005). Once controlling for other factors in the regression of Model 1 it was found that members of two-worker households actually travel $2 \%$ less than those of one-worker families. 
While going against intuition, this result reconfirms the empirical research suggesting that members of two-worker households travel the same or less than one-worker households.

The question of the complementarity of partner trip distance was broached in Model 3 and Model 4. In both cases it was observed that partner's commute distance had a positive impact on individual commute distance. This is consistent with Plaut's conclusion that partner trip distance is complementary. Further examination of these findings, however, contradicts Plaut's further conclusion that this complementarity also implied that partner's do not trade-off commuting distance. While Model 3, and in particular the coefficient of partner's commute distance does not allow us to answer the question of trading-off, Model 4 does. In particular the coefficient on the variable longest-shortest commuting distance allows us to test the hypothesis that partners trade-off. This coefficient is positive thus implying that as one partner's commute distance increases, so does the other's. At the same time, the coefficient (an elasticity) is less than one. This implies that for every $1 \%$ increase in a partner's distance, total commute distance increases by less than $1 \%$. This implies that an increase in the longest commute distance, must result in a decrease in the shortest distance, and as such, that partners are indeed trading-off each other's commute distances.

Finally, Model 4 (and the coefficient on the variable workplace 1 - home - workplace2 angle), while not providing any insight into the question of the complementarity of partner commute distances, does provide insight into the question of whether two-worker households try to decrease commuting distances. In particular, the coefficient on this variable indicates that households apply strategies to decrease their total commuting distance.

There are at least two areas that would be interesting to explore with respect to this research in the future. First, there exists a variety of job-housing balance measures used in the 
transportation and land-use literature. In our study, we used accessibility to jobs as well as circuity to address this issue. Other measures from the literature on excess commuting (e.g. theoretical minimum commute) are increasingly be considered as indicators of jobs-housing balance (see e.g. (Layman, 2010) ). In future work it would be interesting to test them as explanatory variables to explain two-worker household commute distance. Second, residential self-selection is an important issue that is not accounted for in our models. This is due to the fact that relevant data necessary for modeling household location are not available in the OD survey. It would be interesting to attempt to account for it in future research.

Altogether, this research serves to better understand the behaviour of two-worker households with respect to commuting distance and residence workplace configuration. Twowoker households appear to travel less than one-worker households. While partner commute distances are complementary, this does not mean they do not trade-off commute distance. In fact, the results suggest the opposite. Moreover, we also note that two-worker households on average do adjust their household work configuration to reduce overall commuting distance. Perhaps the most intriguing question to emerge from this research is the question of what explains the fact that two-worker households commute less than one-worker households? In other words, it remains intuitive that two-worker households ought to travel more than one-worker households; the problem is that they don't. This should be a priority for research in this field.

\section{ACKNOWLEDGEMENTS}

The authors wish to thank Daniel Bergeron and AMT for access to the Montreal OriginDestination survey data analyzed in this paper. This research was funded by the Natural Sciences and Engineering Research Council of Canada (NSERC), the Social Science Research Council of 
Canada (SSHRC) and Canada Research Chairs. Last but not least we would like to thank the three anonymous reviewers for their valuable comments and suggestions through the review process. 


\section{REFERENCES}

Adams, J. S. (1969). Directional bias in intra-urban migration. Economic Geography, 45(4), 302323.

Agence métropolitaine de transport. (2003). Enquête origine-destination 2003. Montréal, QC: AMT, STM, RTL, STL, CIT, Gouvernement du Québec.

Alonso, W. (1964). Location and Land Use. Cambridge, Massachussetts: Harvard University Press.

Boussauw, K., Neutens, T., \& Witlox, F. (2010). Relationship between spatial proximity and travel-to-work distance: the effect of the compact city. Regional Studies, 46(6), 687-706. doi: 10.1080/00343404.2010.522986

Boussauw, K., Van Acker, V., \& Witlox, F. (2012). Excess travel in non-professional trips: why look for it miles away? Tijdschrift voor economische en sociale geografie, 103(1), 20-38. doi: 10.1111/j.1467-9663.2011.00669.x

Clark, W. A. V., Huang, Y. Q., \& Withers, S. D. (2003). Does commuting distance matter? Commuting tolerance and residential change. Regional Science and Urban Economics, 33(2), 199-221.

Clark, W. A. V., \& Wang, W. F. W. (2005). Job access and commute penalties: Balancing work and residence in Los Angeles. [Article]. Urban Geography, 26(7), 610-626.

Coffey, W., \& Shearmur, R. (2001). The identification of employment centres in Canadian metropolitan areas: the example of Montreal, 1996. Canadian Geographer-Geographe Canadien, 45(3), 371-386.

Costa, D. L., \& Kahn, M. E. (2000). Power couples: Changes in the locational choice of the college educated, 1940-1990. Quarterly Journal of Economics, 115(4), 1287-1315.

Curran, C., Carlson, L. A., \& Ford, D. A. (1982). A theory of residential location decisions of 2worker households. Journal of Urban Economics, 12(1), 102-114.

Deding, M., Filges, T., \& van Ommeren, J. (2009). Spatial mobility and commuting: The case of two-earner households. Journal of Regional Science, 49(1), 113-147. doi: 10.1111/j.1467-9787.2008.00595.x

El-Geneidy, A., \& Levinson, D. (2006). Access to destinations: Development of accessibility measures. In U. o. M. Department of Engineering (Ed.), Access to Destinations Study. Minneapolis, $\mathrm{MN}$.

Giuliano, G., \& Small, K. A. (1993). Is the journey to work explained by urban structure? Urban Studies, 30(9), 15.

Gordon, P., Kumar, A., \& Richardson, H. W. (1989). Gender differences in metropolitan travel behavior. [Article]. Regional Studies, 23(6), 499-510.

Green, A. E. (1997). A question of compromise? Case study evidence on the location and mobility strategies of dual career households. Regional Studies, 31(7), 641-657.

Hamilton, B. W. (1982). Wasteful commuting. Journal of Political Economy, 90(5), 18.

Hansen, W. G. (1959). How accessibility shapes land use. Journal of the American Planning Association, 25(2), 73-76.

Hanson, S., \& Hanson, P. (1980). Gender and urban activity patterns in Uppsala, Sweden. [Article]. Geographical Review, 70(3), 291-299.

Johansson, M. (2005). Childhood influences on adult travel mode choice. Paper presented at the International Conference of Traffic and Transport Psychology. 
Johnston-Anumonwo, I. (1992). The influence of household type on gender differences in work trip distance. Professional Geographer, 44(2), 161-169.

Kim, S. (1995). Excess commuting for 2-worker households in the Los Angeles Metropolitan Area. Journal of Urban Economics, 38(2), 166-182.

Layman, C. H., M. (2010). Comparing Methods for Measuring Excess Commuting and JobsHousing Balance: Empirical Analysis of Land Use Changes. Transportation Research Record(2174), 110.

Levinson, D. (1998). Accessibility and the journey to work. Journal of Transport Geography, 6(1), 11-21.

Levinson, D., \& El-Geneidy, A. (2009). The minimum circuity frontier and the journey to work. Regional Science and Urban Economics, 39(6), 732-738. doi:

10.1016/j.regsciurbeco.2009.07.003

Madden, J. F. (1980). Urban land-use and the growth in two-earner households. American Economic Review, 70(2), 191-197.

Madden, J. F. (1981). Why women work closer to home. Urban Studies, 18(2), 181-194.

Marion, B., \& Horner, M. (2007). Comparison of socioeconomic and demographic profiles of extreme commuters in several U.S. metropolitan statistical areas. Transportation Research Record: Journal of the Transportation Research Board, 2013(-1), 38-45. doi: 10.3141/2013-06

Mok, D. (2007). Do two-earner households base their choice of residential location on both incomes? Urban Studies, 44(4), 723-750. doi: 10.1080/00420980601184745

Murphy, E. (2012). Urban spatial location advantage: the dual of the transportation problem and its implications for land-use and transport planning. Transportation Research Part A: Policy and Practice, 46(1), 91-101. doi: http://dx.doi.org/10.1016/j.tra.2011.09.017

Plaut, P. O. (2006). The intra-household choices regarding commuting and housing. Transportation Research Part a-Policy and Practice, 40(7), 561-571. doi: 10.1016/j.tra.2005.10.001

Shearmur, R. (2006). Travel from home: An economic geography of commuting distances in Montreal. Urban Geography, 27(4), 330-359.

Simpson, W. (1987). Workplace location, residential location, and urban commuting. Urban Studies, 24(2), 119-128.

Singell, L. D., \& Lillydahl, J. H. (1986). An empirical analysis of the commute to work patterns of males and females in two-earner households. Urban Studies, 23(2), 119-129.

Sultana, S. (2005). Effects of married-couple dual-earner households on metropolitan commuting: Evidence from the Atlanta metropolitan area. Urban Geography, 26(4), 328352.

Sultana, S. (2006). What about dual-earner households in jobs-housing balance research? An essential issue in transport geography. Journal of Transport Geography, 14(5), 393-395. doi: $10.1016 /$ j.jtrangeo.2006.06.004

Turner, T., \& Niemeier, D. (1997). Travel to work and household responsibility: new evidence. Transportation, 24(4), 397-419.

Van Ham, M., \& Hooimeijer, P. (2009). Regional differences in spatial flexibility: Long commutes and job related migration intentions in the Netherlands. Applied Spatial Analysis and Policy, 2(2), 129-146.

van Ommeren, J. (2000). Job and residential search behaviour of two-earner households. Papers in Regional Science, 79(4), 375-391. 
van Ommeren, J., Rietveld, P., \& Nijkamp, P. (1998). Spatial moving behavior of two-earner households. Journal of Regional Science, 38(1), 23-41.

van Ommeren, J., Rietveld, P., \& Nijkamp, P. (1999). Impacts of employed spouses on jobmoving behavior. International Regional Science Review, 22(1), 54-68.

Vandersmissen, M. H., Villeneuve, P., \& Thériault, M. (2003). Analyzing changes in urban form and commuting time. Professional Geographer, 55(4), 446-463.

White, M. J. (1977). Model of residential location choice and commuting by men and women workers. Journal of Regional Science, 17(1), 41-52.

White, M. J. (1986). Sex-differences in urban commuting patterns. American Economic Review, 76(2), 368-372.

White, M. J. (1988). Urban commuting journeys are not "wasteful". Journal of Political Economy, 96(5), 13.

Zwerts, E., Allaert, G., Janssens, D., Wets, G., \& Witlox, F. (2010). How children view their travel behaviour: a case study from Flanders (Belgium). Journal of Transport Geography, 18(6), 702-710. doi: http://dx.doi.org/10.1016/j.jtrangeo.2009.10.002 